\title{
CRIAR EDUCACÃ̃O
}

Revista do Programa de Pós-Graduação em Educação - UNESC

\section{$\rightarrow$ 요 है \\ unesc \\ PPG

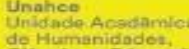 ediunesc}

Criar Educação, Criciúma, v. 8, nº 2, ago/dez 2019.- PPGE - UNESC - ISSN 2317-2452

\section{EDUCAÇÃO FÍSICA CRÍTICO-SUPERADORA E PAULO FREIRE: UM DIÁLOGO POSSÍVEL}

Vidalcir Ortigara ${ }^{1}$

Gabriel Pessi Da Rolt ${ }^{2}$

\begin{abstract}
Resumo: O objetivo deste trabalho é articular princípios da Pedagogia Libertadora de Paulo Freire com a metodologia de ensino Crítico-Superadora, apoiada na Pedagogia Histórico-Crítica e na teoria de aprendizagem histórico-cultural, analisando elementos relevantes para a formação humana. Adotou-se como procedimento metodológico a pesquisa bibliográfica. Os resultados deste estudo possibilitaram ressaltar a importância do princípio da curiosidade epistemológica de Freire e do confronto e contraposição de saberes do Coletivo de Autores para a formação dos sujeitos, resultando em um diálogo entre ambos.
\end{abstract}

Palavras-chave: Paulo Freire. Educação Física. Crítico-Superadora.

\section{EDUCACIÓN FÍSICA CRÍTICA-SUPERADORA Y PAULO FREIRE: UN DIÁLOGO POSIBLE}

Resumen: El objetivo de este trabajo es articular principios de la Pedagogía Libertadora de Paulo Freire con la metodología de enseñanza Crítico-Superadora, apoyada en la Pedagogía Histórico-Crítica y en la teoría del aprendizaje histórico-cultural, analizando elementos relevantes para la formación humana. Se adoptó como procedimiento metodológico la investigación bibliográfica. Los resultados de este estudio posibilitar resaltar la importancia del principio de la curiosidad epistemológica de Freire y de la confrontación y contraposición de saberes del Colectivo de Autores para la formación de los sujetos, resultando en un diálogo entre ambos.

Palabras clave: Paulo Freire. Educación Física. Crítico-superación

\section{CRITICAL-SUPERVISORY PHYSICAL EDUCATION AND PAULO FREIRE: A POSSIBLE DIALOGUE}

Abstract: The objective of this work is to articulate principles of Paulo Freire's Liberating Pedagogy with the Critical-Overcoming teaching methodology, supported by HistoricalCritical Pedagogy and on the theory of historical-cultural learning, analyzing relevant

\footnotetext{
${ }^{1}$ Doutor em Educação. Professor do Programa de Pós-Graduação em Educação na Universidade do Extremo Sul Catarinense.vdo@unesc.net

2 Licenciado em Educação Fisica pela Universidade do Extremo Sul Catarinense. gabriel.rolt@hotmail.com
} 


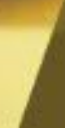

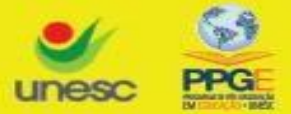

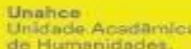 ediunesc}

Criar Educação, Criciúma, v. 8, n², ago/dez 2019.- PPGE - UNESC - ISSN 2317-2452 elements for human formation. Bibliographic research was adopted as a methodological procedure. The results of this study made it possible to emphasize the importance of the principle of Freire's epistemological curiosity and the confrontation and contrast of knowledge from the Collective of Authors for the formation of subjects, resulting in a dialogue between both.

Keywords: Paulo Freire. PE. Critical-Overcoming.

\section{INTRODUÇÃO}

Ao longo do contexto histórico, a educação brasileira passou por diversas transformações, que foram da proposição tradicional, passan do pelo movimento dos pioneiros com o escolanovismo, até as teorias críticas contemporâneas (GHIRALDELLI Jr., 2004, SOARES, 1994). A educação tradicional se caracteriza pelo professor assumir papel central no processo de ensino-aprendizagem e ser o responsável por transmitir de forma acabada os conhecimentos acumulados e sistematizados pela humanidade. De acordo com Saviani (2012, p.7) "as críticas à pedagogia tradicional formuladas a partir do final do século XIX foram, aos poucos, dando origem a uma outra teoria da educação. Essa teoria mantinha a crença no poder da escola e em sua função de equalização social." O professor agiria como um estimulador e orientador da aprendizagem cuja iniciativa principal caberia aos próprio alunos.

Inconformados com essa teoria de educação no Brasil, pensadores desenvolveram teorias para uma educação mais crítica. Entre eles, destacamos Paulo Freire (2017, p. 21), com sua compreensão educacional caracterizada, em suas próprias palavras, como "[...] 'ético-crítico-política da educação' que tem como base o diálogo que desenvolve a conscientização, com o objetivo de formar cidadãos críticos e transformadores."

A Pedagogia Libertadora freireana oferece princípios para uma educação transformadora, que o autor acredita contribuírem decisivamente para libertar os oprimidos. Tais princípios são, entre outros: conscientização, práxis, diálogo e criticidade. 

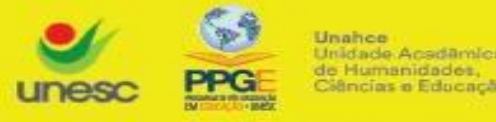

Criar Educação, Criciúma, v. 8, n², ago/dez 2019.- PPGE - UNESC - ISSN 2317-2452 Acompanhando o movimento pedagógico crítico, no âmbito específico da Educação Física, a proposta teórico-metodológica Crítico-Superadora é uma base para o seu ensino que se estruturou a partir da pedagogia Histórico-Crítica (LIBÂNEO, 1985; SAVIANI, 2012). Buscou os fundamentos psíquico-pedagógicos na teoria Histórico-Cultural (SCALCON, 2002) de autores como Alexei Leontiev (1981, s/d) e Lev Vygotsky (1996). A proposição Crítico-Superadora toma a Educação Física como disciplina escolar que trata pedagogicamente de temas da cultura corporal, ou seja, práticas corporais expressivas como os jogos e brincadeiras, a ginástica, as lutas, as danças e os esportes (COLETIVO DE AUTORES, 1992). Para seus autores, os conteúdos da Educação Física devem ser abordados com a finalidade da "apreensão do desenvolvimento sócio-histórico das próprias atividades corporais e à explicitação das suas significações objetivas." (COLETIVO DE AUTORES, 1992, p. 64).

Muito se tem discutido no campo da Educação Física, na atualidade, sobre as propostas metodológicas para seu ensino que surgiram a partir da segunda metade da década de 1980 (BRACHT, 1999). As discussões em geral procuraram explicitar cada uma delas, enfatizando suas diferenças. Na esfera da pedagogia, Freire vem sofrendo ataques de diferentes modos, dentro e fora da academia. Em defesa do pensamento do patrono da educação brasileira, neste trabalho pretendemos subverter a linha dominante dos debates. Procuramos evidenciar um diálogo possível entre os princípios pedagógicos da Pedagogia Libertadora de Paulo Freire e as bases metodológicas do ensino de Educação Física Crítico-Superadora (COLETIVO DE AUTORES, 1992). Ressaltamos que essa relação é salutar para o debate em defesa da formação ampliada das novas gerações, para a qual a apropriação dos conhecimentos da "cultura corporal ou movimento" (BRACHT, 1999, p. 81) é um dos elementos imprescindíveis na direção da formação de sujeitos críticos em suas ações na perspectiva da transformação social.

O primeiro passo da investigação foi procurar o que há de produção em relação à temática. Realizamos busca nas bases Google Acadêmico com os descritores "educação física crítico-superadora" e "educação física crítica 


\section{unesc PPGE}

Criar Educação, Criciúma, v. 8, n², ago/dez 2019.- PPGE - UNESC - ISSN 2317-2452 emancipatória", que resultou em 333 trabalhos. Pela leitura dos resumos dos trabalhos, verificamos que 112 trabalhos relatavam experiências pedagógicas e a aproximação com as bases teóricas anunciadas pelos propositores. $\mathrm{Na}$ base de dados Scielo, realizamos a mesma busca e chegamos a 595 trabalhos. Ao realizar as leituras dos resumos, encontramos 273 trabalhos que relatam experiências pedagógicas ou o histórico das propostas teórico-metodológicas. Com os descritores "pedagogia histórico-crítica" e "pedagogia libertadora" nas bases Google acadêmico encontramos 3.280 trabalhos. A leitura dos resumos dos trabalhos nos revelou 197 trabalhos que apresentam a história e articulação dessas duas pedagogias. Na base do Scielo encontramos 2.960 trabalhos. Por meio das leituras dos resumos, identificamos 342 que aproximam as duas pedagogias e a história das concepções. Não localizamos, no entanto, estudos que estabelecem um diálogo entre a proposta de Educação Física Crítico-superadora e a Pedagogia Libertadora freireana. Em parte já esperávamos por isso, uma vez que, como apontamos anteriormente, a perspectiva teórico-metodológica Crítico-Superadora indica que suas bases pedagógicas estão na perspectiva Histórico-Crítica de Saviani (2012). Porém, consideramos que 0 diálogo com a pedagogia freireana deva estar permanentemente aberto para que a própria Educação Física amplie suas reflexões, seja reafirmando ou reestruturando suas convicções educacionais. Logo, avaliamos como relevante apresentar um possível diálogo - entendido na perspectiva freireana - entre a Pedagogia Libertadora e a metodologia de ensino da Educação Física Crítico-Superadora.

Considerando tais questões, optamos por apresentar as linhas gerias da Pedagogia Liberadora e articulá-las aos pressupostos e orientações da proposta teórico-metodológica Crítico-Superadora, estabelecendo um diálogo entre ambos.

\section{DIÁlOGO DA PEDAGOGIA LIBERTADORA COM A EDUCAÇÃO FíSICA CRÍTICO-SUPERADORA}




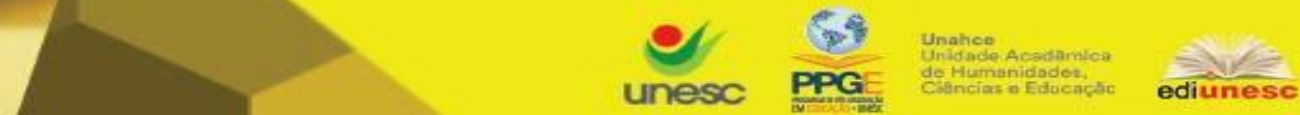

Criar Educação, Criciúma, v. 8, n²2, ago/dez 2019.- PPGE - UNESC - ISSN 2317-2452

Para compreendermos alguns princípios da Pedagogia Libertadora elaborada por Paulo Freire, precisamos adentrar seu contexto histórico.

Acreditamos que, ao longo da história, as propostas educacionais surgiram a partir das necessidades de atender predominantemente os interesses de uma determinada classe. Para a classe dominante a educação tinha o caráter de pedagogia tradicional, em que o papel do docente era transmitir os conhecimentos acumulados pela humanidade e sistematizados logicamente com a perspectiva do desenvolvimento das técnicas solicitadas pelo desenvolvimento do mercado de trabalho (SAVIANI, 2012).

Contrapondo-se a essa perspectiva, Freire (2017) propôs a Educação Libertadora, portanto, fez críticas e contribuições para uma transformação educacional. $\mathrm{O}$ autor caracterizou a pedagogia tradicional com a metáfora das ações bancárias - em que o processo de ensino centrava-se no caráter narrativo do professor e ao aluno cabia a tarefa de assimilar o narrado - em que o professor "deposita" uma quantidade de conhecimento e depois, mediante um instrumento, "verifica o saldo", o que ficou na cabeça do aluno. O educador aparece como seu indiscutível agente, como o sujeito cuja tarefa indeclinável é "encher" os educandos dos conteúdos de sua narração. Geralmente os conteúdos estão desconectados da totalidade, sem vinculação com as significações de sua realidade. Ao final do processo o educador avalia os educandos a partir daquilo que "depositou". A educação, dessa maneira, torna-se "um ato de depositar", em que os educandos são os depositários e o educador o depositante. A questão da concepção "bancária" reduz a tentativa de fazer dos seres humanos serem mais.

Na visão "Bancária" da educação, o "saber" é uma doação dos que se julgam sábios aos que julgam nada saber. Doação que se funda numa das manifestações instrumentais da ideologia da opressão - a absolutização da ignorância, que constitui o que chamamos de alienação da ignorância, segundo a qual esta se encontra sempre no outro. (FREIRE, 2017, p. 81).

Assim como Freire partiu de uma crítica às relações concretas da pedagogia tradicional para desenvolver uma pedagogia que oriente uma educação que 


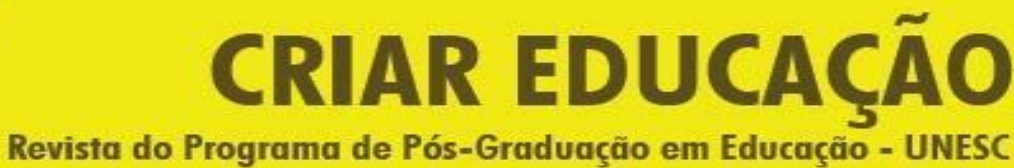

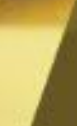

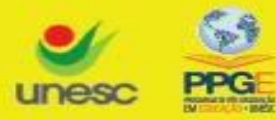

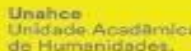 \\ PPG \\ ediunesc}

Criar Educação, Criciúma, v. 8, n², ago/dez 2019.- PPGE - UNESC - ISSN 2317-2452 promova a consciência crítica dos alunos, a perspectiva metodológica CríticoSuperadora também nasceu de uma crítica à educação tradicional da Educação Física.

Nos anos 1980 a Educação Física brasileira passou por um movimento denominado de "renovador", destacando-se uma teoria geral do movimento que permitia, como meio de formação, superar os limites da psicomotricidade, do tecnicismo, do modelo "esportivizado" (BRACHT, 1999). Esse movimento contrapunha-se, entre outras perspectivas, ao princípio de que a função seria estimular o desenvolvimento psicomotor através do exercício, desencadeando mudanças de hábitos, ideias e sentimentos. A Educação Física escolar teria como objetivo o desenvolvimento motor para auxiliar as outras disciplinas escolares (COLETIVO DE AUTORES, 1992).

De acordo com os princípios humanistas, apresentou-se a tendência ligada ao movimento chamado Esporte Para Todos, que se caracteriza como movimento alternativo ao esporte de rendimento. Essa concepção se impregna de uma antropologia que coloca a autonomia do ser humano no centro, mas não põe em debate as condições objetivas para que tal autonomia possa efetivamente ser exercida (COLETIVO DE AUTORES, 1992). Nesse movimento de renovação surgem várias proposições, não necessariamente orientadas para a superação de seu aspecto acrítico, como foram a proposta desenvolvimentista (MANOEL, 1988) e o "movimento de atualização e renovação do paradigma da aptidão física, levado a efeito com base no mote da promoção da saúde." (BRACHT, 1999, p. 79). A proposta Crítico-Superadora apresentou-se como alternativa a esse movimento, centrando-se no processo de formação do sujeito situado sócio-historicamente, de forma que possa, ao apropriar-se das práticas corporais, "constatar, interpretar, compreender e explicar" (COLETIVO DE AUTORES, 1992, p. 87) a realidade de tais práticas.

Após apresentarmos brevemente o processo histórico da Pedagogia Libertadora e da base metodológica do ensino de Educação Física CríticoSuperadora inferindo que ambas surgem da necessidade de superar uma pedagogia 
Criar Educação, Criciúma, v. 8, n², ago/dez 2019.- PPGE - UNESC - ISSN 2317-2452 tradicional, procuraremos evidenciar algumas aproximações entre as duas teorias com o intuito de estabelecer um possível diálogo entre elas.

Devido ao percurso histórico da educação, Freire (2017) trabalhou preocupado com o processo de humanização e desumanização que ocorre no contexto histórico, no contexto real, concreto, objetivo. Ele parte do princípio de que os homens são seres inconclusos, diferentemente dos animais, que são apenas inacabados, mas não históricos. Os homens se sabem inacabados, o que lhes confere a possibilidade de atuação consciente no rumo de sua formação, processo que nunca se acaba. "Sua inconclusão é própria da experiência vital. Onde há vida, há inacabamento. Mas só entre mulheres e homens o inacabamento se tornou consciência." (FREIRE, 2015, p. 50).

De acordo com Freire (1983), o nível de consciência - ingênuo ou crítico está associado à forma como se conhece o mundo e esta com a situação real vivida. Não é qualquer aprendizado um modo de tomar consciência do real: a educação bancária não promove esta apreensão do real, muito ao contrário, se distancia dela. A educação bancária promove o aprendizado ingênuo, a Educação Libertadora promove o aprendizado crítico. Cada nível de consciência irá promover uma apreensão do mundo e esta irá possibilitar um tipo de atuação no mundo. A conscientização é a passagem da consciência ingênua para a crítica. Está além da tomada de consciência. Conscientizar não significa, de nenhum modo, ideologizar ou propor palavras de ordem. Se a conscientização abre caminho à expressão das insatisfações sociais é porque estas são componentes reais de uma situação de opressão. E também a conscientização não significa "tomar consciência", pois conscientização irá implicar sempre em práxis. Tomar consciência é apenas o primeiro passo.

Logo, a educação bancária não oferece o suporte necessário para um desenvolvimento humano crítico, porque no atual contexto a educação desenvolvese no limite dos ditames da lógica do mercado de trabalho. Por isso Paulo Freire procurou desenvolver uma educação que desse o suporte necessário para que os sujeitos tenham a consciência crítica de que são seres inacabados, que possam 


\section{Cricin

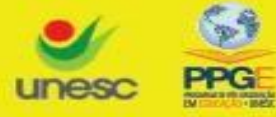

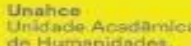 \\ PPG

Criar Educação, Criciúma, v. 8, n², ago/dez 2019.- PPGE - UNESC - ISSN 2317-2452 aprender e conscientizar-se a partir de seu processo histórico. Porém, na lógica da divisão de classes essa possibilidade fica reduzida, impedindo que os homens se libertem, e nega sua vocação de poder lutar pela sua liberdade. Então, o problema da lógica do mercado de trabalho é que ela afasta a pessoa de fazer uma leitura crítica da realidade e de seu lugar nela, naturalizando os lugares sociais como questões de mérito individual, por isto é ingênua. E assim vai reproduzindo uma estrutura social injusta, uma vez não permitir que todos possam realizar sua condição ontológica de "ser mais".

Assim como a Pedagogia Libertadora desenvolveu princípios de conscientização dos sujeitos, a Crítico-Superadora também se preocupa com a superação da pedagogia tradicional da Educação Física, que não colabora para o desenvolvimento de sujeitos críticos. Para Freire, a educação, em geral tradicional, não desenvolve o homem crítico. Para a proposta Crítico-Superadora, uma das preocupações é desenvolver no homem a consciência de que são seres históricos, culturalmente desenvolvidos, e suas práticas corporais foram historicamente produzidas nas condições objetivas que condicionam as relações de produção e reprodução da vida humana. Por exemplo, "a espécie humana não tinha, na época do homem primitivo, a postura corporal do homem contemporâneo. Aquele era quadrúpede e este é bípede" (COLETIVO DE AUTORES, 1992, p. 38). Portanto, é uma conquista da produção humana que se transformou em patrimônio cultural da humanidade.

A consciência dos sujeitos é ampliada pelo conhecimento científico.

[...] o conhecimento é tratado de forma a ser retraçado desde sua origem ou gênese, a fim de possibilitar ao aluno a visão de historicidade, permitindo-Ihe compreender-se enquanto sujeito histórico, capaz de interferir nos rumos de sua vida privada e da atividade social sistematizada. (COLETIVO DE AUTORES, 1992, p. 40).

O conhecimento é abordado metodologicamente na lógica dialética materialista em sua totalidade. Essa organização didática permite compreendê-lo como produto histórico, em que os alunos apropriam-se de maneira a ampliar as 


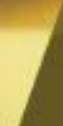

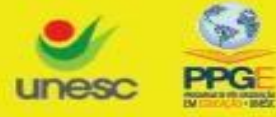

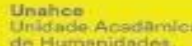 ediunesc}

Criar Educação, Criciúma, v. 8, n²2, ago/dez 2019.- PPGE - UNESC - ISSN 2317-2452 referências de pensamento, desenvolvendo a consciência, superando 0 conhecimento do senso comum, que Freire chama de conhecimento ingênuo.

A explicitação dos princípios da educação bancária evidencia que eles não permitem o desenvolvimento da consciência crítica dos homens. Por isso Freire (2017) considera que a ampla formação dos homens é negada na injustiça, na exploração, na opressão, na violência dos opressores. Mas afirma o anseio de liberdade, de justiça, de luta dos oprimidos, pela recuperação de sua humanidade "roubada". A desumanização ocorre na distorção da vocação do ser mais dos homens. Por conseguinte, a luta pela humanização ocorre pelo trabalho livre da opressão, pela desalienação, pela afirmação dos homens como pessoas, como seres para si. "É possível porque a desumanização, mesmo que um fato concreto na história, não é, porém destino dado, mas resultado de uma 'ordem' injusta que gera a violência dos opressores e esta, o ser menos." (FREIRE, 2017, p. 41).

Nesse aspecto, a superação da exploração busca a libertação que não chega por acaso, mas pela práxis de sua busca. Busca que inicia pelo conhecimento e reconhecimento da necessidade de lutar por ela. Aquela que tem de ser forjada com ele e não para ele, enquanto homens ou povos, na luta incessante de recuperar sua humanidade. Nesse particular Freire (2017) defende que a pedagogia faça da opressão e de suas causas objeto da reflexão dos oprimidos, que resulte em seu engajamento necessário na luta por sua libertação.

A práxis é ação e reflexão dos homens sobre o mundo para transformá-lo. Sem ela é impossível a superação da contradição opressor-oprimido (FREIRE, 2017, p. 52). Ação e reflexão ocorrem a partir da palavra, que encontramos no diálogo.

E que é o diálogo? É uma relação horizontal de A com B. Nasce de uma matriz crítica e gera criticidade (Jaspers). Nutre-se do amor, da humildade, da esperança, da fé, da confiança. Por isso, só o diálogo comunica. E quando os dois pólos do diálogo se ligam assim, com amor, com esperança, com fé um no outro, se fazem críticos na busca de algo. Instala-se, então, uma relação de simpatia entre ambos. Só aí há comunicação (FREIRE, 1983, p. 107). 


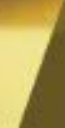

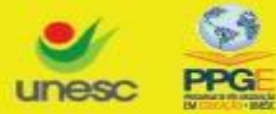

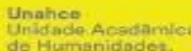 ediunesc}

Criar Educação, Criciúma, v. 8, n², ago/dez 2019.- PPGE - UNESC - ISSN 2317-2452 Freire ainda afirma (1983, p.108) "O diálogo então são as questões vitais para nossa ordenação política, mas em todos os sentidos do nosso ser, pela virtude da crença no homem e nas suas possibilidades e significação".

O antidiálogo é oposto de uma Educação Libertadora, pois trata de depositar, de invadir o espaço cultural dos sujeitos. Para que a invasão cultural seja efetivada, o invasor cultural deve conquistar seus objetivos. Faz-se necessário que esta ação seja auxiliada por outras que, servindo a ela, são distintas às dimensões da teoria antidialógica. "Na verdade, manipulação e conquista, expressões da invasão cultural e, ao mesmo tempo, instrumentos para mantê-la, não são caminhos de libertação. São caminhos de 'domesticação'." (FREIRE, 2015, p. 51).

O princípio do diálogo caminha junto com o da criticidade. A criticidade surge a partir da curiosidade ingênua que, por sua vez, está associada com o "saber do senso comum"; criticizando-se, aproximando-se de forma cada vez mais metodicamente rigorosa do objeto cognoscível, torna-se curiosidade epistemológica. "A superação se dá na medida em que a curiosidade ingênua, sem deixar de ser curiosidade, pelo contrário, continuando a ser curiosidade, se criticiza." (FREIRE, 2015, p. 32).

Para Freire (2017) a curiosidade epistemológica implica no estudo sistematizado, o qual se afasta do conhecimento de senso comum e chega ao conhecimento crítico científico, em que há uma relação da práxis (ação e reflexão), que terá um diálogo de sujeitos que terão consciência ingênua em alguns pontos e crítica em outros, a curiosidade epistemológica levará à passagem do conhecimento de senso comum - ingênuo - para o conhecimento científico - crítico em situação de diálogo. De outro modo não poderia ser diálogo, mas tenderia a ser um monólogo, ou "invasão cultural".

Porém, esse diálogo tem que se dar pelo respeito, amor, esperança e confiança. Assim a curiosidade ingênua, que é aquela que tem o conhecimento do senso comum, dialoga com a "epistemológica", aquela do conhecimento sistematizado. Nessa troca desperta a curiosidade epistemológica, logo, o sujeito se torna crítico, consciente de sua libertação. Não é possível uma superação da 
Criar Educação, Criciúma, v. 8, nº 2, ago/dez 2019.- PPGE - UNESC - ISSN 2317-2452 ingenuidade a não ser pelo conhecimento. É pelo diálogo que o sujeito começa a ter uma consciência que luta pela práxis, assim se tornando crítico. Isso exige superar a educação bancária que domestica os sujeitos, desumanizando-os.

A perspectiva Crítico-Superadora não atribui relevância à "vocação" dos homens, mas às necessidades de atender aos interesses imediatos e históricos da classe trabalhadora no contexto da organização das relações de produção capitalista. Os interesses imediatos da classe trabalhadora focalizam a necessidade de sobrevivência, luta no cotidiano, direito ao emprego, ao salário, alimentação, transporte, saúde, educação, enfim, as condições dignas de existência. Os interesses imediatos da classe proprietária correspondem às necessidades de acumular riquezas, gerar renda, ampliar o consumo, o patrimônio. Já seus interesses históricos correspondem à necessidade de se garantir no poder (COLETIVO DE AUTORES, 1992). Os interesses históricos da classe trabalhadora se aproximam da ideia de "vocação ontológica" apresentada por Freire (2017), se expressam "através da luta e da vontade política para tomar a direção da sociedade, construindo a hegemonia popular." (COLETIVO DE AUTORES, 1992, p. 24). Os autores reafirmam que ela "[...] se expressa através de uma ação prática, no sentido de transformar a sociedade de forma que os trabalhadores possam usufruir do resultado de seu trabalho" (COLETIVO DE AUTORES, 1992, p. 24).

Quando o Coletivo de Autores (1992) afirma que é na ação prática que se desenvolve a luta da classe trabalhadora, quer dizer que é a partir da prática social e sobre a ação dos homens na sociedade que esse movimento se desenvolve, ou seja, pela práxis. Percebe-se que tanto Paulo Freire quanto o Coletivo de Autores afirmam que a luta da superação se dá pelo princípio da práxis. Para Bottomore (2001, p. 292),

A expressão práxis refere-se, em geral, a ação, a atividade, e, no sentido que lhe atribui Marx, à atividade livre, universal, criativa e auto criativa, por meio da qual o homem cria (faz, produz), e transforma (conforma) seu mundo humano e histórico e a si mesmo; atividade específica ao homem, que o torna basicamente diferente de todos os outros seres. Nesse sentido, o homem pode ser considerado um ser da práxis, entendida a expressão como o 


\section{CRIAR EDUCACÃ̃O}

Revista do Programa de Pós-Graduação em Educação - UNESC

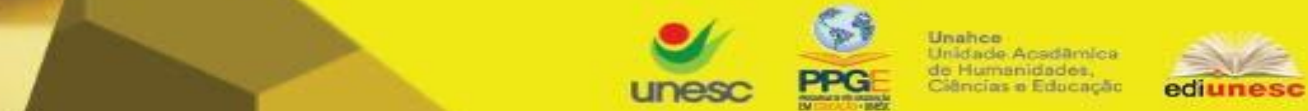

Criar Educação, Criciúma, v. 8, n² 2, ago/dez 2019.- PPGE - UNESC - ISSN 2317-2452 conceito central ao marxismo, e este como a "filosofia" (ou melhor, o "pensamento") da "práxis".

O princípio da práxis da luta pela superação do atual modo de organização das relações de vida e atendimento dos interesses históricos da classe trabalhadora consiste no trato com o conhecimento na direção epistemológica. A superação, para a perspectiva teórico-metodológica Crítico-Superadora, é orientada pelo conhecimento científico e desenvolvida coletivamente, ou seja, não há superação dos sujeitos de forma individual, esse movimento é feito pelo conjunto dos sujeitos, com o princípio do confronto e contraposição de saberes, pelo "compartilhar significados construídos no pensamento do aluno através de diferentes referências: o conhecimento científico ou saber escolar é o saber construído enquanto resposta às exigências do seu meio cultural informado pelo senso comum." (COLETIVO DE AUTORES, 1992, p. 31). Percebemos que não há uma "desvalorização" do conhecimento que o aluno possui, mas a possibilidade de ele confrontá-lo com outras referências de pensamento, alterando, assim, seu nível de consciência.

O confronto do saber popular (senso comum) com o conhecimento científico universal selecionado pela escola, o saber escolar, é, do ponto de vista metodológico, fundamental para a reflexão pedagógica. Isso porque instiga 0 aluno, ao longo de sua escolarização, a ultrapassar o senso comum e construir formas mais elaboradas de pensamento (COLETIVO DE AUTORES, 1992, p. 31).

O professor é aquele que, com um nível diferenciado de conhecimento em relação aos alunos, estabelece um diálogo com eles, proporciona o aprendizado do objeto de estudo e favorece o desenvolvimento da consciência crítica para que possam, entre outras coisas, lutar pelos interesses da classe trabalhadora. Para Paulo Freire, esse movimento se desenvolveria pelo despertar da curiosidade epistemológica, o que se aproxima dos princípios propostos pelo Coletivo de Autores.

Tal perspectiva de educação orienta a formação para a efetivação da libertação dos oprimidos, o que exige uma organização do conteúdo programático da educação ou da ação política. Esta última expõe ao povo, através de certas 
Criar Educação, Criciúma, v. 8, n², ago/dez 2019.- PPGE - UNESC - ISSN 2317-2452 contradições básicas, sua situação existencial, concreta, presente como problema que, por sua vez, o desafia e lhe exige resposta, não só em nível intelectual, mas em nível da ação. O momento de busca, com diálogo da educação como prática da liberdade, é o de investigar o universo temático que é o conjunto de temas geradores (FREIRE, 2017). Essa dinâmica, na concepção Crítico-Superadora, é realizada pelos princípios curriculares de seleção de conteúdo: relevância social do conteúdo, contemporaneidade do conteúdo e adequação às possibilidades sociocognoscitivas do aluno (COLETIVO DE AUTORES, 1992). A relevância social dos conteúdos implica compreender o seu sentido e significado para a reflexão pedagógica escolar. "Este deverá estar vinculado à explicação da realidade social concreta e oferecer subsídios para a compreensão dos determinantes sóciohistóricos do aluno, particularmente a sua condição de classe social." (COLETIVO DE AUTORES, 1992, p. 31). O princípio da contemporaneidade do conteúdo deve garantir aos discentes o conhecimento do que tem de mais moderno no mundo contemporâneo. Quanto ao princípio de adequação às possibilidades sociocognoscitivas dos alunos, ou seja, considerar a capacidade cognitiva e a prática social dos discentes, seu conhecimento e suas possibilidades enquanto sujeitos históricos, este pode ser relacionado com os níveis de desenvolvimento propostos por Vygotsky (2012).

O que o Coletivo de Autores (2009) aborda como relevância social, contemporaneidade e adequação às possibilidades sociocognoscitivas do aluno, Paulo Freire chama de organização do conteúdo programático da educação ou da ação política, que é o tratamento dado ao conhecimento na seleção dos conteúdos de ensino. Após selecionar o conteúdo, conforme o Coletivo de Autores, é preciso organizar e sistematizar a metodologia com a qual será tratado. Segundo Freire (2017), essa relação se desenvolverá pelas situações-limites e atos-limites. Para o Coletivo de Autores (1992), esse movimento se dá pela tematização dos conteúdos orientada pelos princípios de confronto e contraposição de saberes, simultaneidade dos conteúdos enquanto dados da realidade, espiralidade da incorporação das referências do pensamento e provisoriedade do conhecimento. 


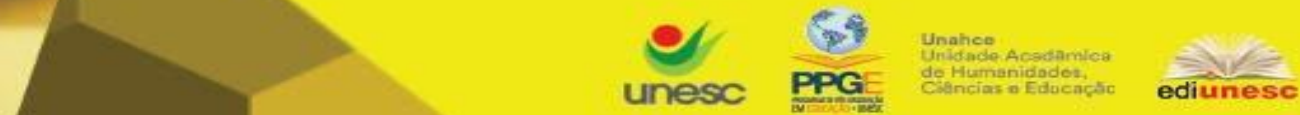

Criar Educação, Criciúma, v. 8, n² 2, ago/dez 2019.- PPGE - UNESC - ISSN 2317-2452 de terminalidade. Os autores reafirmam que "É fundamental para o emprego desses princípios apresentar o conteúdo ao aluno, desenvolvendo a noção de historicidade retraçando-o desde a sua gênese, para que este se perceba enquanto sujeito histórico (COLETIVO DE AUTORES, 1992, p. 33).

Para a perspectiva Crítico-Superadora, a seleção e organização ocorrem orientadas pelos princípios de trato com o conhecimento da relevância social, contemporaneidade, adequação às possibilidades sociocognoscitivas, contraposição de saberes, simultaneidade, espiralidade e provisoriedade, a que Freire chamaria de situações-limites, que surgem das situações concretas e por isso não podem ser estabelecidos com antecedência.

Esses são alguns princípios que Paulo Freire desenvolveu na proposta de uma Pedagogia Libertadora. Pedagogia que está desenvolvida para a emancipação dos oprimidos e dos opressores, que se desdobra em dois momentos:

O primeiro em que os oprimidos vão desvelando o mundo da opressão e comprometem-se, na práxis, como a sua transformação; o segundo em que, transformada a realidade opressora, esta pedagogia deixa de ser do oprimido e passa a ser a pedagogia dos homens em processo de permanente libertação (FREIRE, 2017, p. 57).

A proposta Crítico-Superadora está desenvolvida para uma superação dos sujeitos pelo conhecimento científico. A assimilação dos conhecimentos ocorre no desenvolvimento de um plano de atuação docente que se compõe de três momentos: no primeiro, são realizadas as considerações sobre o conteúdo e objetivos; no segundo, ao qual se dedica a maior parte do tempo disponível, promove-se a apreensão do conhecimento; no terceiro, se amarram as conclusões, avalia-se o realizado e levantam-se perspectivas para as aulas seguintes. Assim, a metodologia Crítico-Superadora vai além de uma Educação Física tradicional.

A Pedagogia Libertadora e a proposição teórico-metodológica de ensino da Educação Física Crítico-Superadora acreditam que o sistema educacional deva transcender uma organização que atenda aos interesses da classe dominante. Para isso a educação necessita ser libertadora, buscando o conhecimento no diálogo 


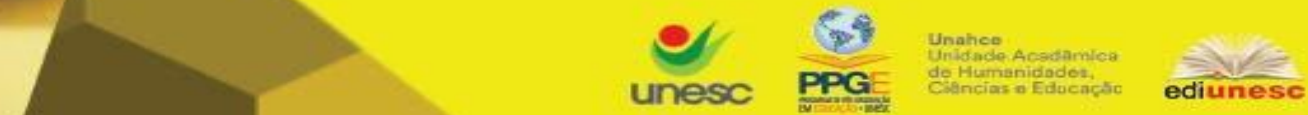

Criar Educação, Criciúma, v. 8, n², ago/dez 2019.- PPGE - UNESC - ISSN 2317-2452 entre conhecimento popular e epistemológico de maneira que os sujeitos, ao se apropriarem dos conhecimentos produzidos historicamente pela humanidade, desenvolvidos na práxis humana, desenvolvam uma consciência emancipada.

O princípio da curiosidade epistemológica referida por Freire $(2015$, p. 86) pode ser relacionado com o princípio de trato metodológico do conhecimento de confronto e contraposição de saberes proposto pelo Coletivo de Autores (1992, p. 31). Ademais, consideramos que este princípio tenha caráter geral, isto é, orienta todas as propostas pedagógicas críticas, transformadoras, que têm o intuito de ampliar o pensamento das pessoas tornando-as sujeitos conscientes críticos de sua liberdade. Tal condição, que defendemos amparados nos referenciais aqui apresentados, ocorre pelas reflexões no intuito de superar o conhecimento do senso comum orientado pelo conhecimento crítico científico.

\section{CONSIDERAÇÕES FINAIS}

A perspectiva assumida neste trabalho, a formação humana para Paulo Freire e para o Coletivo de Autores, é permeada pelos princípios que intentam a superação da educação tradicional. A formação defendida tem a finalidade de desenvolver a consciência pela práxis e na práxis, em busca do conhecimento científico produzido historicamente em diálogo com o senso comum, assumindo sua inconclusão na luta por desvencilhar-se das amarras que o sistema social contemporâneo nos impõe.

A organização e escolha do conteúdo, para Freire, é realizada pelos temas geradores, com os quais sistematizará os conteúdos programáticos a serem desenvolvidos nas situações-limites e atos-limites. Essa relação está descrita pelo Coletivo de Autores no âmbito do trato com o conhecimento, que direciona a escolha, sistematização e tratamento metodológico dos conteúdos. Esse processo está orientado pelos princípios da relevância social do conteúdo, contemporaneidade, adequação às possibilidades sociocognoscitivas, confronto e contraposição de saberes, simultaneidade, espiralidade e provisoriedade do conhecimento. 


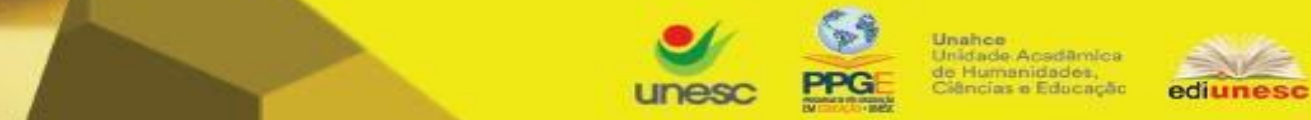

Criar Educação, Criciúma, v. 8, n², ago/dez 2019.- PPGE - UNESC - ISSN 2317-2452 $\mathrm{O}$ desenvolvimento do estudo possibilitou um diálogo entre a Pedagogia Libertadora e a proposta teórico-metodológica do ensino da Educação Física CríticoSuperadora que resultou em uma comunicação entre elas, analisando a importância do princípio da curiosidade epistemológica de Paulo Freire e do confronto e contraposição de saberes do Coletivo de Autores para a formação de sujeitos críticos. Ressaltamos com isso a importância de Paulo Freire para os debates no âmbito da educação e da Educação Física de modo que ultrapassem algumas leituras e interpretações realizadas da Pedagogia Libertadora. Os princípios educacionais freireanos para o desenvolvimento educacional brasileiro ainda carecem de maiores estudos, em particular para o ensino da Educação Física.

\section{REFERÊNCIAS}

BOTTOMORE, Tom. Dicionário do pensamento marxista. Rio de Janeiro: Jorge Zahar, 2001.

BRACHT, Valter. A constituição das teorias pedagógicas da educação física. Cadernos Cedes, Campinas, n. 48, p. 69-88, 1999.

COLETIVO DE AUTORES. Metodologia do ensino de educação física. São Paulo: Cortez, 1992.

FREIRE, Paulo. Educação como prática da liberdade. 18 ed. Rio de Janeiro: Paz e Terra, 1983.

. Pedagogia da Autonomia: saberes necessários a prática educativa. 50 ed. São Paulo: Paz e Terra 1996.

. Extensão ou comunicação? 17 ed. São Paulo: Paz e Terra, 2015.

2017.

Pedagogia do oprimido. 63 ed. Rio de Janeiro, São Paulo: Paz e Terra,

GUIRALDELLI Jr., Paulo. Educação Física Progressista: a pedagogia Críticosocial dos conteúdos e a Educação Física brasileira. 9 ed. São Paulo: Loyola, 2004.

LEONTIEV, Alexis. Desenvolvimento do psicquismo. São Paulo: Moraes, s/d. 


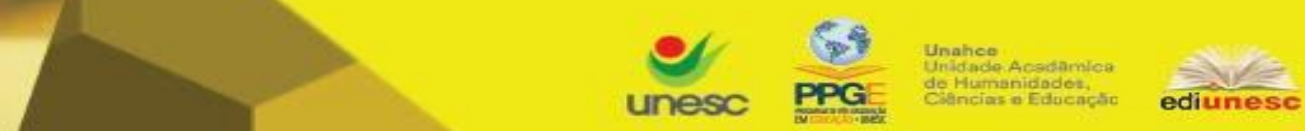

Criar Educação, Criciúma, v. 8, n²2, ago/dez 2019.- PPGE - UNESC - ISSN 2317-2452 Educación, 1981.

Activididad, Consciencia y Personalidad. La Habana: Pueblo y

LIBÂNEO, José Carlos. Democratização da escola pública: a pedagogia críticosocial dos conteúdos. São Paulo: Loyola, 1985.

MANOEL, Edison de Jesus. Educação física escolar: fundamentos de uma abordagem desenvolvimentista. São Paulo: E.P.U., 1988.

SAVIANI, Demerval. Escola e Democracia. 42 ed. Campinas: Autores Associados, 2012.

SCALCON, Suze. À procura da unidade psicopedagógica: articulando a psicologia histórico-cultural com a pedagogia histórico-crítica. Campinas: Autores Associados, 2002.

VYGOTSKY, Lev S. A Formação Social da Mente. São Paulo: Martins Fontes, 2012. 1996.

Lev S. Pensamento e Linguagem. 6 reimp. São Paulo: Martins Fontes,

Lev S. Aprendizagem e Desenvolvimento Intelectual na Idade Escolar. In. LEONTIEV, Alexis et all. Psicologia e Pedagogia: bases psicológicas da aprendizagem e do desenvolvimento. 5 reimp. São Paulo: Centauro, 2011.

Recebido 30 de novembro 2018

Aprovado 25 de maio de 2019. 